\title{
Metabolic and functional connectivity provide unique and complementary insights into
} cognition-connectome relationships

Katharina Voigt ${ }^{1,2}$, Emma X. Liang ${ }^{2}$, Bratislav Misic ${ }^{3}$, Phillip G.D. Ward ${ }^{2}$, Gary F. Egan 1,

$$
{ }^{2}, \text { \& Sharna D. Jamadar }{ }^{1,2}
$$

${ }^{1}$ School of Psychological Sciences and Turner Institute for Brain and Mental Health, Monash University, Victoria, Australia

${ }^{2}$ Monash Biomedical Imaging, Monash University, Victoria, Australia

${ }^{3}$ McConnell Brain Imaging Centre, Montréal Neurological Institute, McGill University, Montréal, Québec, Canada.

*Corresponding author:

Dr Katharina Voigt

Turner Institute for Brain and Mental Health

Monash Biomedical Imaging

770 Blackburn Road, Clayton, VIC 3800, Australia

Katharina.voigt@monash.edu 


\begin{abstract}
A major challenge in current cognitive neuroscience is how functional brain connectivity gives rise to human cognition. Functional magnetic resonance imaging (fMRI) describes brain connectivity based on cerebral oxygenation dynamics (hemodynamic connectivity), whereas [18 F]-fluorodeoxyglucose functional positron emission tomography (FDG-fPET) describes brain connectivity based on cerebral glucose uptake (metabolic connectivity), each providing a unique characterisation of the human brain. How these two modalities differ in their contribution to cognition and behaviour is unclear. We used simultaneous resting-state FDG-fPET/fMRI to investigate how hemodynamic connectivity and metabolic connectivity relate to cognitive function by applying partial least squares analyses. Results revealed that while for both modalities the frontoparietal anatomical subdivisions related the strongest to cognition, using hemodynamic measures this network expressed executive functioning, episodic memory, and depression, while for metabolic measures this network exclusively expressed executive functioning. These findings demonstrate the unique advantages that simultaneous FDG-PET/fMRI has to provide a comprehensive understanding of the neural mechanisms that underpin cognition and highlights the importance of multimodality imaging in cognitive neuroscience research.
\end{abstract}

\title{
Keywords:
}

Cognition, functional connectivity, metabolic connectivity, functional positron emission tomography 


\section{Introduction}

The human connectome is a comprehensive map of neural connections, that describes the brain as a complex network of interconnected brain regions (Sporns, 2013; Sporns et al., 2005). Non-invasive neuroimaging methods provide us with the opportunity to characterise the functionality of brain connectivity on multiple levels (Raichle, 2009). As such, brain connectivity is a multidimensional concept that is defined by its measurement tool. Blood oxygenation level dependent (BOLD) functional magnetic resonance imaging (fMRI) has been the dominant tool to characterise functional brain connectivity, based on the temporal coherence of spontaneous, low-frequency large-amplitude changes in blood oxygenation whilst an individual is at rest (Biswal et al., 1995; Raichle, 2011). BOLD-fMRI provides a haemodynamic-based surrogate measure of neuronal activity at a high spatial and temporal resolution, but is confounded by non-neuronal components (e.g., heart rate, respiration, blood volume; Liu, 2017; Ward et al., 2020). Positron Emission Tomography (PET) scanning using the glucose analogue F18-fluordoxyglucose (FDG) provides the opportunity to characterise metabolic elements of brain connectivity based on cerebral glucose update (Yakushev et al., 2017). In contrast to BOLD-fMRI, FDG-PET is a quantifiable index of neuronal activity capturing cerebral glucose uptake at the synapses. The integration of the two modalities in a simultaneous MR-PET system (Chen et al., 2018; Judenhofer et al., 2008) offers the unique opportunity to undertake multidimensional neuroimaging studies to examine the interaction between hemodynamic and metabolic aspects of brain connectivity. How these elements of human brain connectivity (i.e., hemodynamic and metabolic) individually and jointly contribute to human cognition and behaviour remains a formidable challenge of contemporary cognitive neuroscience.

A central assumption in cognitive neuroscience is that cognitive processes are emergent properties of neural communication, which is predicted by the coherent and flexible 
oscillatory activity between neural ensembles (Avena-Koenigsberger et al., 2018; Barack and Krakauer, 2021). Two views of how the brain as a neural network relates to cognition have emerged: the domain-specific connectome-cognition view and the global connectomecognition view. According to the specific view, connectivity is domain-specific and multiple networks arise for distinct cognitive domains. According to the global view, the overall wiring of connectome gives rise to global cognitive functioning. A single set of connectivity patterns predict cognitive functioning across different domains, such as attention, memory, executive functioning.

Evidence from fMRI research using multivariate analytic approaches to examine brain-behaviour relationships has revealed support for both views (e.g., Goyal et al., 2020; Smith et al., 2015; Ziegler et al., 2013; Zimmermann et al., 2018). In support of the domainspecific connectome-cognition view, Zimmermann and collegues (2018) found unique orthogonal sets of resting-state hemodynamic connectivity clusters that were associated with specific cognitive domains. Inter- and intra-hemispheric resting-state hemodynamic connectivity in the frontoparietal, occipital, temporal, and cingulate areas was negatively associated with processing speed, executing functioning, and working memory. Intelligence was related to a separate set of resting-state hemodynamic connectivity in cortico-cortical and cortico-subcortical networks, such as the caudate and putamen. In contrast, in support of the global view, Smith and others (2015) revealed a single mode of large-scale resting-state hemodynamic connectivity patterns capturing a wide set of behavioural (e.g., intelligence, verbal ability) and demographic variables (e.g., age, sex, income, drug use). This result has recently been replicated by Goyal and others (2020). These studies reveal initial insights into how coherent, low-frequency BOLD fMRI signalling in spatially distinct brain areas (i.e., hemodynamic connectivity) relates to cognition. However, as the BOLD signal represents a proxy of neural activity that is shaped by non-neuronal contributions to the BOLD signal 
(Liu, 2017; Ward et al., 2020), this considerably restricts our existing understanding of connectome-cognition systems to haemodynamic correlates.

Recent developments in continuous radiotracer delivery and improved PET signal detection of dual-modality magnetic resonance (MR)-PET scanners, has allowed the study of continuous glucose uptake with substantially improved temporal resolution (e.g., 60 seconds or less; Jamadar et al., 2021; Rischka et al., 2018; Villien et al., 2014). This novel method, termed "functional" FDG-PET (FDG-fPET), provides the opportunity to characterise the metabolic connectome beyond previous covariance measures resulting from static PET (Jamadar et al., 2021) and thus, approaches similar within-subject time-course correlational descriptions as exist for BOLD-fMRI hemodynamic connectivity. Using the fPET approach, we recently found that the metabolic FDG-fPET connectome showed moderate similarity with the BOLD-fMRI hemodynamic connectivity at rest, with the highest similarity between functional and metabolic connectivity obtained primarily with the superior and frontoparietal cortical areas (Jamadar et al., 2021). These initial findings suggest the complementary potential of describing the human connectome via fMRI and FDG-fPET. However, how resting-state metabolic connectivity derived from FDG-fPET relates to cognition and how it differs in their predictive ability from BOLD-fMRI hemodynamic connectivity remains unknown.

The present study aimed to investigate whether (1) a single global or multiple distinct connectivity pattern maps onto cognition, and whether (2) the connectome-cognition relationship is different for hemodynamic and metabolic connectivity derived from a novel FDG-fPET methodology (Jamadar et al., 2020; Jamadar et al., 2021). We acquired FDGfPET data with high temporal resolution of $16 \mathrm{~s}$ to measure glucose metabolic connectivity, and simultaneously acquired BOLD-fMRI data with a temporal resolution of $2.45 \mathrm{~s}$ from 26 participants. Participants completed a neuropsychological cognitive test battery, which 
bioRxiv preprint doi: https://doi. org/10.1101/2021.09.06 459214 this version posted September 7, 2021. The copyright holder for this preprint (which was not certified by peer review) is the author/funder, who has granted bioRxiv a license to display the preprint in perpetuity. It is made available under aCC-BY-NC-ND 4.0 International license.

resulted in 14 cognitive outcome variables indexing cognition across several domains (verbal memory, attention, executive functioning). We used partial least squares (PLS) to map orthogonal patterns of brain-behaviour relationships (Krishnan et al., 2011; McIntosh and Lobaugh, 2004; McIntosh and Misic, 2013) (Figure 1). As evidence for both connectomecognition views has been reported for fMRI data (e.g., Goyal et al., 2020; Smith et al., 2015; Ziegler et al., 2013; Zimmermann et al., 2018), we undertook and exploratory analysis to investigate how hemodynamic and metabolic connectomes map onto cognition. However, as hemodynamic and metabolic connectomes have been shown to reveal distinct connectivity patterns (Jamadar et al., 2021), we hypothesised that both would provide a unique, but complementary insight, into the connectome-cognition relationship.

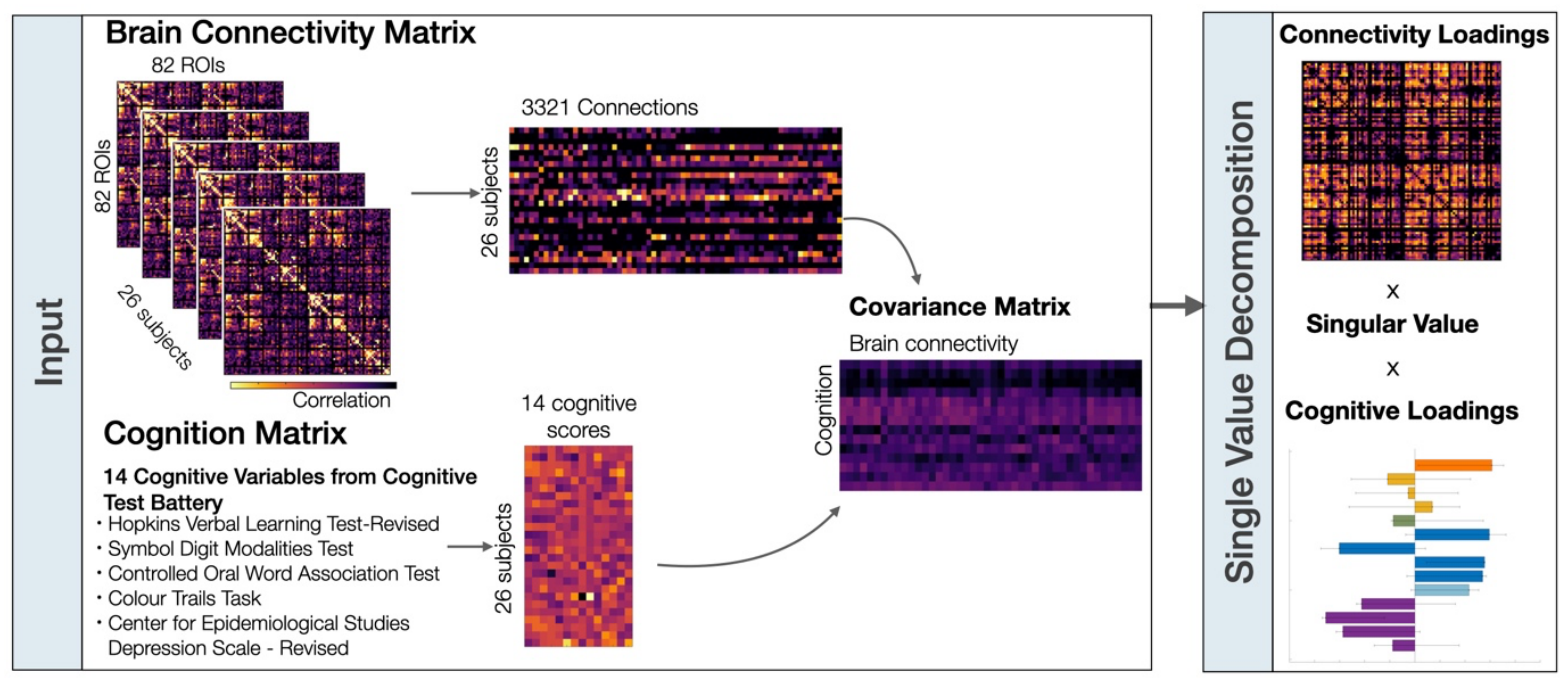

Figure 1. Overview of partial least squares analyses. Two partial least squares analyses were performed on both brain connectivity data sets (i.e., hemodynamic connectivity, metabolic connectivity) separately. The brain connectivity matrices were first sorted by stacking the upper triangle elements from each participants' matrices. The rows of the brain connectivity and cognitive matrices correspond to participants and the columns correspond to either the brain connections or cognitive scores. The covariance between the brain connectivity and cognition matrices was computed across participants, resulting in a rectangular connectivity- 
cognition covariance matrix. This covariance matrix was then subjected to singular value decomposition. Refer to Materials and Methods for details.

\section{Results}

We first provide an overview of the cognitive outcome variables of the neuropsychological test battery. Next, we describe the hemodynamic (i.e., fMRI functional connectivity) and metabolic connectivity (i.e., FDG-fPET functional connectivity) across participants. Finally, we show how both connectivity maps relate to cognition and quantify their differences.

\section{Cognitive measures}

Participants completed a neuropsychological test battery that described distinct cognitive domains across 14 outcome variables (Table 1). Most cognitive variables correlated significantly within each cognitive test, but not across tests (Figure 2) suggesting each cognitive test measured distinct cognitive domains. An exception was that individuals with higher depression scores on the CESD-R were overall slower during congruent trials of the Stroop task (i.e., reading colour names; $\mathrm{r}(24)=0.54,95 \%$ CI $[0.28,0.83], \mathrm{p}<0.05$ ). Also, performance during the Symbol Digits Modality test, correlated negatively with performance during the second part of the Colour Trail test (CT2 score) $(\mathrm{r}(24)=-0.48,95 \%$ CI $[-0.83,-$ 0.28], $\mathrm{p}<0.05)$. For the Partial Least Squares analyses, the total score from the Stroop congruent trials was removed as there was no variability across participants, as all participants received the maximum score of 112 .

Table 1. Cognitive outcome variables from the cognitive battery.
Cognitive
Cognitive Domain
Outcome
Descriptive Statistics
Test
Variable

Mean SD Range




\begin{tabular}{|c|c|c|c|c|c|}
\hline \multirow[t]{6}{*}{ HVTL-R } & $\begin{array}{l}\text { Verbal episodic } \\
\text { memory }\end{array}$ & Total Recall & 26.96 & 3.72 & $19-33$ \\
\hline & & $\begin{array}{l}\text { Delayed } \\
\text { Recall }\end{array}$ & 9.73 & 1.61 & 7-12 \\
\hline & & Retention & $93.46 \%$ & $10.93 \%$ & $73-100 \%$ \\
\hline & & Rate & & & \\
\hline & & Recognition & 11.19 & 1.02 & $8-12$ \\
\hline & & Score & & & \\
\hline SDMT & Processing Speed & Total Score & 56.19 & 5.72 & $\begin{array}{l}45.45- \\
68.18\end{array}$ \\
\hline \multirow[t]{4}{*}{ Stroop } & $\begin{array}{l}\text { Executive Function / } \\
\text { Inhibition Control }\end{array}$ & $\begin{array}{c}\text { Incongruent } \\
\text { Score }\end{array}$ & 109.42 & 5.22 & $89-112$ \\
\hline & & $\begin{array}{c}\text { Incongruent } \\
\text { RT }\end{array}$ & 102.50 & 19.67 & $55-147$ \\
\hline & & $\begin{array}{c}\text { Congruent } \\
\text { RT }\end{array}$ & 53.58 & 10.11 & $39-89$ \\
\hline & & $\begin{array}{l}\text { Frontal Lobe } \\
\text { Dysfunction }\end{array}$ & 0.26 & 0.13 & $0.2-0.8$ \\
\hline
\end{tabular}

Score

\begin{tabular}{llllll}
\hline COWAT & Executive Function / & Total Score & 42.50 & 11.92 & 21-68 \\
& Verbal Fluency & & & \\
& & & & & \\
\hline Colour Trails & Executive Function / & CT1 Score & 30.88 & 8.59 & $17-50$
\end{tabular}

Cognitive Flexibility

CT2 Score $\quad 56.88 \quad 8.77 \quad 45-75$




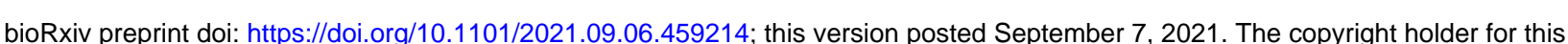
preprint (which was not certified by peer review) is the author/funder, who has granted bioRxiv a license to display the preprint in perpetuity. It is made available under aCC-BY-NC-ND 4.0 International license.

\begin{tabular}{ccccc}
\hline Interference & 0.96 & 0.54 & $0.11-2.38$ \\
Index & & & &
\end{tabular}

\begin{tabular}{llllll}
\hline CESD-R & Depression & Total Score & 9.12 & 8.54 & $0-31$
\end{tabular}

Abbreviations: HVTL-R, Hopkins Verbal Learning Test-Revised; SDMT, The Symbol Digit

Modalities Test; COWAT, The Controlled Oral Word Association Test; CESDR-R, Center

for Epidemiologic Studies Depression Scale - Revised; CT, Colour Trails; RT, Reaction

time; SD, Standard Deviation.

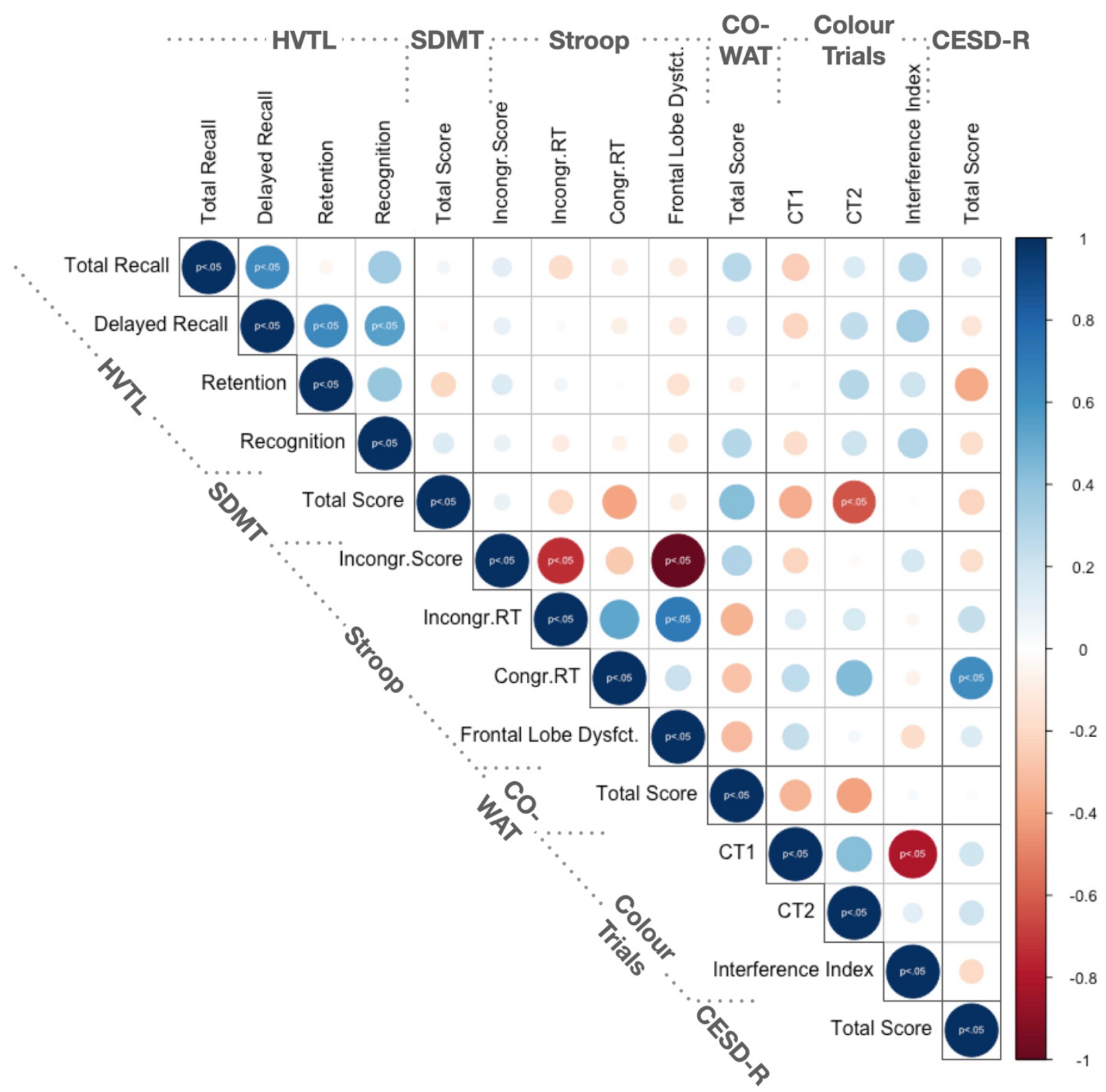


Figure 2. Correlation matrix of 14 cognitive outcome variables obtained from the neuropsychological test battery. Significant relationships are indicated with $p>0.05$ corrected for multiple comparisons using false discovery rate (Benjamini and Hochberg, 1995). Pearson's correlation was performed for continuous and Spearman correlation was performed for ordinal data. Positive relationships $(0 \leq \mathrm{r} \leq 1)$ are indicated in blue and negative relationships $(0>\mathrm{r} \leq-1)$ are indicated in red. Circle size corresponds to the absolute size of the correlation coefficient as indicated by the blue-red coloured scale. Abbreviations: HVLT, Hopkins Verbal Learning Test-Revised; SDMT, Symbol Digit Modality Test; COWAT, Controlled Oral Word Association Test; CESD-R, Center for Epidemiologic Studies Depression Scale - Revised; CT1, Colour Trails 1; CT2, Colour Trails 2; RT, Reaction Time.

\section{Hemodynamic and Metabolic Connectivity}

The haemodynamic and metabolic connectomes have been reported previously (Jamadar et al., 2021; Jamadar et al., 2020) and are included here for completeness. The hemodynamic connectome (Figure 3a) showed medium to strong connectivity within most anatomical subdivisions, both within and between hemispheres. The strongest hemodynamic connectivity ( $\mathrm{r} \geq 0.7$ ) was found bilaterally in the frontal, parietal, and occipital anatomical subdivisions. A number of strong long-range connections included frontoparietal, parietooccipital, and temporoparietal regional connectivity. These long-range connections were evident both within and between hemispheres but were of smaller magnitude than the shortrange and homotopic connections. Subcortical and orbitofrontal regions were the least interconnected regions in the BOLD-fMRI data $(r \geq 0.2)$.

The metabolic connectome (Figure $3 b)$ showed the strongest connectivity $(r \geq 0.15)$ within the frontoparietal areas, which was more apparent within than between hemispheres. 
bioRxiv preprint doi: https://doi org/10.1101/2021.09.06 459214 this version posted September 7, 2021. The copyright holder for this preprint (which was not certified by peer review) is the author/funder, who has granted bioRxiv a license to display the preprint in perpetuity. It is made available under aCC-BY-NC-ND 4.0 International license.

Left-right homotopic connectivity was not visually apparent for subcortical, temporal, and occipital cortices.

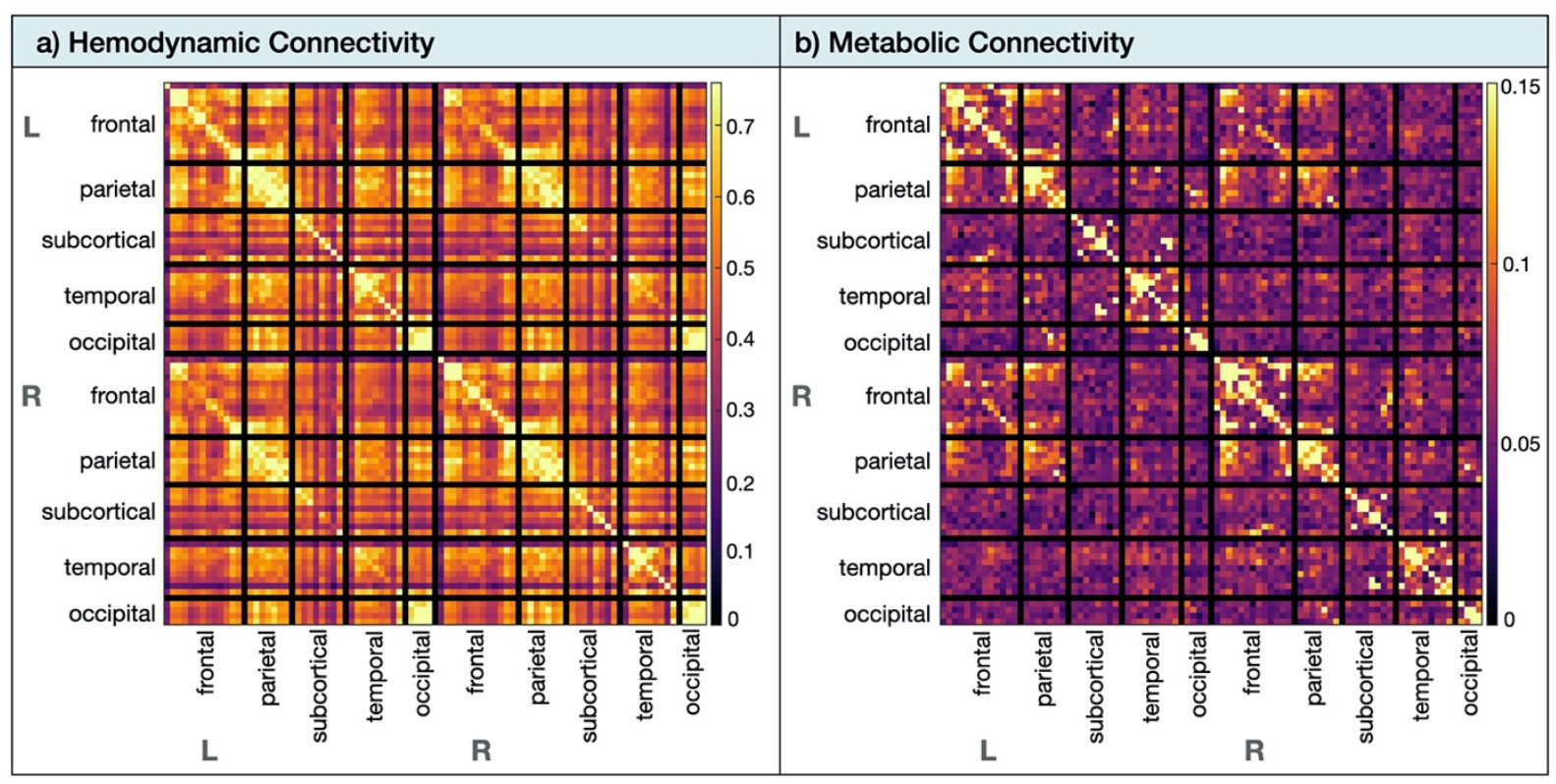

Figure 3. Hemodynamic and metabolic connectivity at rest. (a) The hemodynamic (i.e., fMRI functional connectivity) was thresholded from $0<\mathrm{r}<0.76$. (b) The metabolic connectivity (i.e., fPET functional connectivity) was thresholded from $0<0<0$.15. Abbreviations: L, left; $\mathrm{R}$, right.

\section{Partial Least Squares Results}

The Partial Least Squares (PLS) analyses applied to the fMRI and fPET data sets separately identified one significant latent variable that described the relationship between the hemodynamic connectivity and cognition, and one significant latent variable that described the relationship between the metabolic connectivity and cognition.

\section{Hemodynamic Connectivity and Cognition Relationship}

The PLS analyses revealed that one latent variable captures the relationship between hemodynamic connectivity pattern and cognition $(67.13 \%$ of total covariance; singular value $=39.43, \mathrm{p}=0.003$, permutation testing with 5,000 iterations). The distribution of cognitive loadings revealed that each cognitive variable within each test (Table 1) in general loaded 
uniformly in their direction onto the latent variable (Figure 4ai). For example, all sub-scales of the HVLT loaded negatively onto the latent variable, and all sub-scales of the Stroop loaded positively. Bootstrapped confidence intervals revealed that three cognitive variables were expressed the strongest by the latent variable: participant's depression score (CESD-R score; loading $=0.61,95 \%$ bootstrapped CI $[0.15,0.82])$, inhibition control speed (i.e. the response time in naming a font colour of an incongruent word during the Stroop task; loading $=0.56,95 \%$ bootstrapped CI $[0.18,0.57])$, and memory retention (HVTL retention score; loading $=-0.71,95 \%$ bootstrapped CI $[-0.34,-0.72)$. The hemodynamic connections all loaded strongly positively onto the latent variable (loading $>0.67$; Figure 4aii). The strongest loadings $(r \geq 0.85)$ were found bilaterally in the frontal and parietal anatomical subdivisions. Thresholding the connectivity matrix at the $99^{\text {th }}$ percentile (Jamadar et al., 2020), revealed that $41.4 \%$ of the strongest connections were part of the frontal cortex (e.g., superiorfrontal, middlefrontal, parstriangularis, parsopercularis, medialorbitofrontal, precentral and rostralanteriorcingulate), and $24.1 \%$ of the total strongest connections were part of the parietal cortex (e.g., supramarginal, posteriorcingulate, precuneus, isthmuscingulate). The subcortical areas contained (e.g., caudate, hippocampus, insula, putamen) and the temporal cortex contained $17.2 \%$ of the total strongest connections (i.e., superiortemporal, fusiform, banks), respectively. There were no strong connections in the occipital cortex. Interpreting the cognition loadings together with the brain loadings, the PLS analysis revealed that higher depression, higher inhibitory control speed and lower memory retention are associated with higher hemodynamic connectivity particularly in the frontal and parietal anatomical interhemispheric subdivisions.

\section{Metabolic Connectivity and Cognition Relationship}

The PLS analyses revealed that one latent variable captures the relationship between metabolic connectivity pattern and cognition $(30.77 \%$ of total covariance; singular value $=$ 
24.42, $\mathrm{p}=0.04$, permutation testing with 5,000 iterations). The distribution of cognitive loadings revealed that each cognitive variable within each test (Table 1) loaded generally uniformly and in their direction onto the latent variable (Figure 4bi). The direction of the cognitive loadings was similarly expressed by the latent variable describing the hemodynamic connectivity-cognition relationship. Bootstrapped confidence intervals revealed that all outcome variables of the Stroop task, measuring executive functioning/inhibitory control, loaded strongly positively onto the latent variable. Further, the COWAT score loading $=-0.58,95 \%$ bootstrapped CI $[-0.15,-0.79])$, measuring executive functioning/verbal fluency was also expressed strongly negatively by the latent variable. The metabolic connections loaded mostly positively (loading $>0.54$ ) onto the latent variable (Figure 3bii). However, there were also a few connections that loaded negatively, although very weakly (loading <-0.15) (Appendix Figure S2). These negative loadings were distributed across the brain. The strongest loadings $(r \geq 0.54)$ all loaded positively and were found predominantly in the frontal and parietal anatomical subdivisions. Thresholding the connectivity matrix at the $99^{\text {th }}$ percentile, revealed that $50 \%$ of the strongest connections were part of the frontal cortex (e.g., frontal pole, superior frontal, middle frontal, lateral orbitofrontal, caudal anterior cingulate, precentral) and 33\% of the total strongest connections were part of the parietal cortex (e.g., postcentral, posterior cingulate, pre-cuneus, inferior parietal, superior parietal, supra-marginal). The occipital cortex contained only $8.3 \%$ of the total strongest connections (i.e., lateral occipital) and the subcortical (i.e., thalamus) and temporal cortex (i.e., temporal pole) only $4.2 \%$, respectively. Interpreting the cognition loadings together with the brain loadings, the PLS analysis revealed that higher inhibitory control and lower verbal fluency are associated with predominantly higher metabolic connectivity particularly in the frontal and parietal anatomical subdivisions. 
bioRxiv preprint doi: https://doi org/10.1101/2021.09.06 459214 this version posted September 7, 2021. The copyright holder for this preprint (which was not certified by peer review) is the author/funder, who has granted bioRxiv a license to display the preprint in perpetuity. It is made available under aCC-BY-NC-ND 4.0 International license.

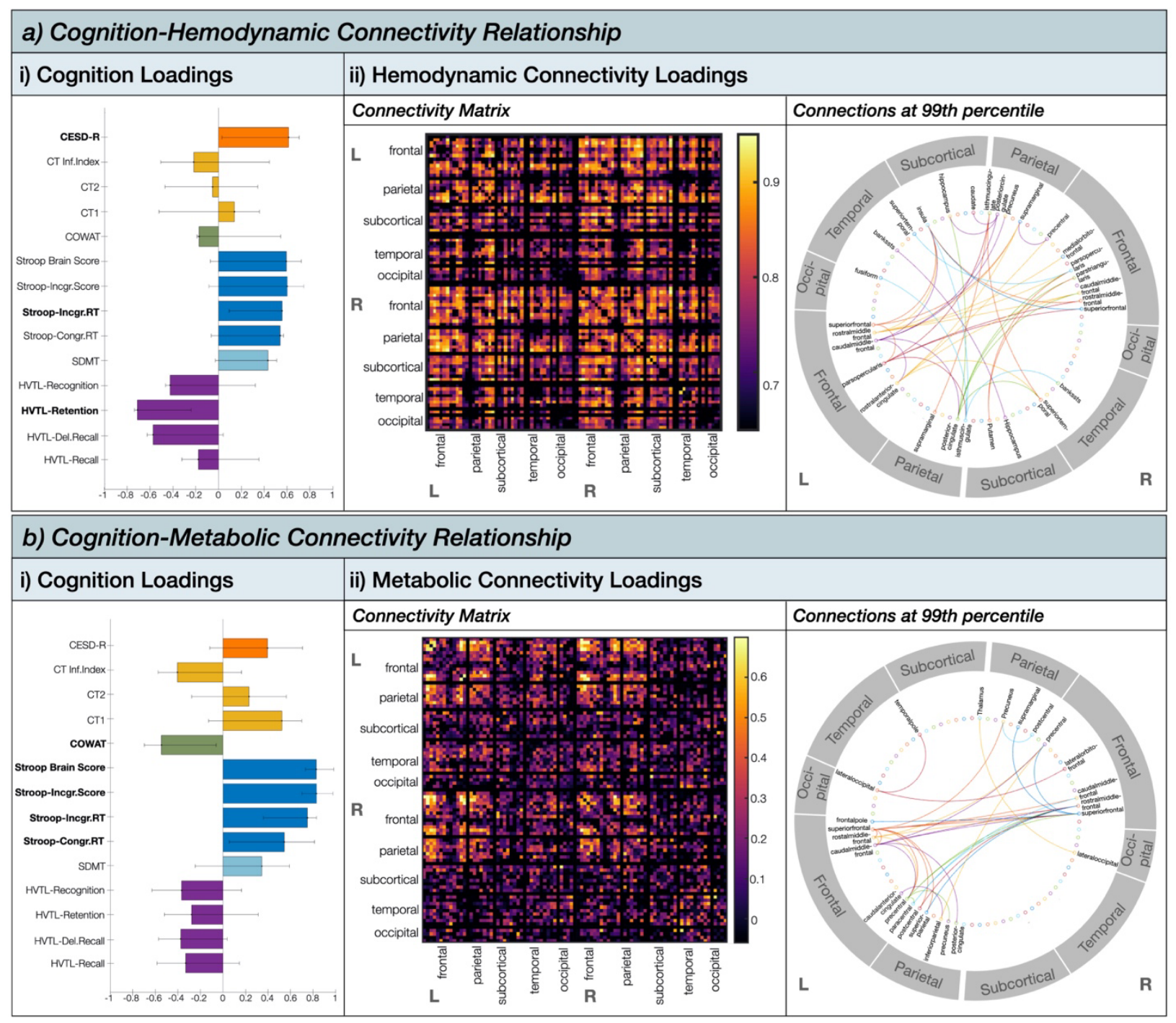

Figure 4. Partial least squares analysis results showing the a) cognition-hemodynamic

connectivity relationship, and b) cognition-metabolic connectivity relationship. (i) Cognition loadings for significant latent variable. Error bars represent 95\% Confidence intervals from bootstrap resampling (5,000 iterations). (ii) Connectivity loadings for significant latent variable. The circular plot shows the strongest anatomical connections thresholded at the $99^{\text {th }}$ percentile.

\section{Differences in Hemodynamic-Cognition and Metabolic-Cognition Relationship}

To compare the connections that contributed to the cognition-metabolic connectivity relationship and those that contributed to the cognition-hemodynamic relationship, we computed the scalar dot product between the brain saliences $(U)$ of the significant latent 
bioRxiv preprint doi: https//doi.org/10.1101/2021.09.06.459214. this version posted September 7 2021. The copyright holder for this preprint (which was not certified by peer review) is the author/funder, who has granted bioRxiv a license to display the preprint in perpetuity. It is made available under aCC-BY-NC-ND 4.0 International license.

variable from both PLS analyses. A cosine value of 1 means that the saliences are identical and 0 means orthogonality or no correlation. This analysis revealed a cosine similarity of 0.23 (i.e., weak relationship) indicating that the effects of the PLS for the hemodynamic-cognition relationship differed from the effects from the metabolic-cognition relationship. This was confirmed by the similarity matrix of each relationship's brain loadings, showing overall little overlap across the two modalities with the most correlation coefficients ranging between -0.1 and 0.1 (Figure 5). The highest similarity between the two modalities $(r>0.4)$ was evident for the frontal and parietal cortex for both hemispheres. The loading matrices were anticorrelated (loading $<-0.3$ ) for occipital and temporal subdivisions.

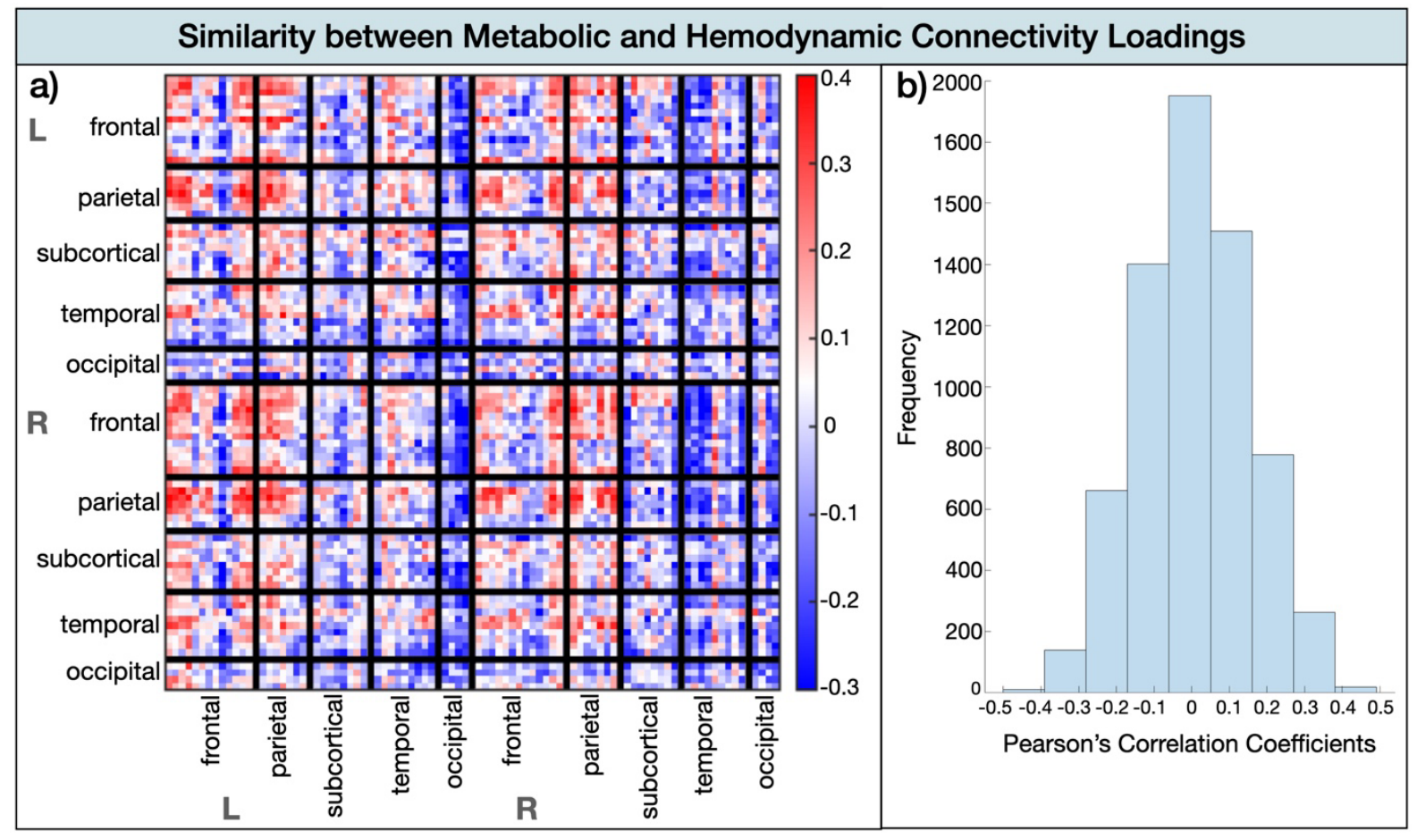

Figure 5. Similarity between the metabolic and hemodynamic connectivity loadings. (a)

Similarity matrix by brain area. (b) Histogram of Pearson's correlation coefficients indicating the frequency of similarity strength. 


\section{Discussion}

The present study used simultaneous resting-state FDG-PET/fMRI to investigate, for the first time, how spatially distant synchronous brain signals measured via cerebrovascular hemodynamic responses (i.e., fMRI; hemodynamic connectivity) and glucose uptake (i.e., FDG-PET; metabolic connectivity) relate to a range of cognitive functions. Our simultaneous fPET and fMRI acquisition at a high temporal resolution enabled multimodal within-subject analyses of resting-state brain activity without the confound of intra-individual differences (e.g., fatigue, nutrient intake, blood chemistry) that occur when measuring both modalities not simultaneously. We applied Partial Least Squares (Krishnan et al., 2011; McIntosh and Lobaugh, 2004) to extract latent variables capturing the maximum covariance between hemodynamic and metabolic connectivity matrices with 14 cognitive measures, including episodic memory, processing speed, executive functioning, and depression. Results revealed that one latent variable captured the relationship between hemodynamic connectivity and cognition and one latent variable captured the relationship between metabolic connectivity and cognition. The cognitive battery was indexing orthogonal cognitive domains. This supports the global connectome-cognition view, which states that a global cognitive factor is accounted by a single set of connections (Goyal et al., 2020b; Smith et al., 2015b). By contrast, our results do not support the domain-specific connectome-cognition view, which would suggest that distinct sets of connections are required to support cognition (e.g., Ziegler et al., 2013; Zimmermann et al., 2018).

Although cognition was expressed globally by one set of connectivity-cognition latent variable, the specificity of how hemodynamic and metabolic connectivity related to cognition varied. For both modalities the frontoparietal anatomical subdivisions related the strongest to cognition (Figure 4), however for hemodynamic responses this network expressed executive functioning, episodic memory, and depression, whereas for metabolic responses this network 
exclusively expressed executive functioning. This is compatible with the argument that metabolic and hemodynamic connectivity provide unique, but complementary insights into cognition (Chen et al., 2018; Hahn et al., 2020; Jamadar et al., 2021; Mier and Mier, 2015; Sala and Perani, 2019; Yakushev et al., 2017).

\section{A global set of metabolic and hemodynamic connections map onto cognition}

Our results support the contention that the overall wiring of a connectivity network has a domain-general role in cognition. Critically, this domain-general characteristic is shared by both the metabolic and hemodynamic processes, indicating that it is a shared characteristic across multiple physiological levels of the human connectome. This finding is in line with classical theoretical proposals that brain networks exhibit a flexible architecture with their functional network assignment to adaptively process changing cognitive demands (Dehaene et al., 1998; Duncan, 2001; Miller and Cohen, 2001). Flexible, domain-general interactions likely allow different information to become quickly integrated and exchanged, leading to a dominant pattern of co-activation across different cognitive states.

In our results, the frontoparietal anatomical subdivisions emerged as the dominant regions supporting a domain-general role in cognition. The frontoparietal anatomical network was previously coined a multi-demand system that is co-activated when performing a diverse range of cognitive demanding tasks, including selective attention, working memory, task switching, response inhibition, conflict monitoring, learning or problem solving (Assem et al., 2020; Chein \& Schneider, 2005; Cole et al., 2014; reviewed by Marek \& Dosenbach, 2018). In line with this general systems role to support information integration and exchange that mediates cognitive operations, damage to the frontoparietal network has been reported to be associated with disorganised behaviour and decreased fluid intelligence (Hearne et al., 2016). Further, this system has been shown to play domain-general protective role against mental health symptoms such as depression (Schultz et al., 2018). 
bioRxiv preprint doi: https://doi.org/10.1101/2021.09.06.459214; this version posted September 7, 2021. The copyright holder for this preprint (which was not certified by peer review) is the author/funder, who has granted bioRxiv a license to display the preprint in perpetuity. It is made available under aCC-BY-NC-ND 4.0 International license.

\section{Metabolic and functional connectivity relate to distinct aspects of cognition}

The behavioural variables loaded uniformly on the latent variables for the metabolic connectivity-cognition and hemodynamic connectivity-cognition pattern but differed in their loading strengths. The fPET metabolic and BOLD-fMRI hemodynamic connectivity had the strongest network configuration in frontoparietal cortices. However, this network seems to relate to distinct cognitive functions for both imaging modalities. Specifically, the restingstate hemodynamic connectivity in this network was positively associated with inhibition, depression and negatively with memory retention. The resting-state metabolic connectivity in this network in turn was associated positively with executive functioning and inhibition; and negatively with executive functioning and verbal fluency.

The cognition-connectivity pattern revealed by fMRI is in strong accord with numerous previous fMRI studies revealing the brain mechanisms underlying cognition. For example, the frontoparietal network, particularly involving the anterior cingulate cortex, precuneus or posterior cingulate cortex, has been shown to be a core network involved in cognitive control monitoring and the facilitation of conflict resolution during a task (Botvinick et al., 2004; Shenhav et al., 2013). Additionally, this flexible and domain-general hub has also been involved in emotional processing, clinical symptoms such as depression (Schultz et al., 2018), and memory (Wallis et al., 2015). These findings are corroborated in the cognition-connectivity patterns observed in this study. In addition to frontoparietal coactivation, the hemodynamic connectivity loadings were also prevalent in cortico-cortical networks, for example involving the insula or hippocampus. The insula is strongly interconnected with frontal and parietal areas supporting its role as a major multimodal network hub that underpins cognition, memory and emotional processing (Contreras et al., 2012; Menon and Uddin, 2010). The hippocampus supports a vast array of memory 
functions, such as retaining information across delays (Jeneson et al., 2011; Müller et al., 2018).

In contrast to the hemodynamic connectivity-cognition relationship, the latent variable expressing the metabolic connectivity-cognition relationship was strongly localised in the frontoparietal areas and associated exclusively with executive functioning. Previous studies have reported that resting-state metabolic connectivity is particularly evident in frontoparietal areas (Shokri-Kojori et al., 2019; Yakushev et al., 2017; Hahn et al., 2019). Here we extend these finding by observing that the co-activation at rest is behaviourally relevant in supporting executive control. We note the existence of a small proportion of negative connections (only $25.22 \%$ of connections) that contributed to the cognition-metabolic connectivity relationship. These negative cognition-connectivity associations can reflect either reduced positive associations or anti-correlations (Hearne et al., 2016). There is also the possibility that these scattered negative loadings (Figure S2) might be a pre-processing epiphenomenon (Jamadar et al., 2020). Future research is needed to investigate whether the small fraction of negative associations in the metabolic connectome are behaviourally meaningful.

The apparent specificity of the cognition-metabolic connectivity relationship, i.e., the exclusive focus on frontoparietal cortices, may be indicative of signal artefacts in either the FDG-fPET or BOLD-fMRI, i.e., reduced signal-to-noise or non-neuronal confounders, respectively. The reduced sensitivity of the FDG-fPET signal must be noted as the processing pipeline, including filters and models, are immature compared to the years of advanced development that has been dedicated to BOLD-fMRI signal processing as reported in the scientific literature. Conversely, this advancement has potentially led to the identification of non-neuronal confounders and spatial artefacts in BOLD-fMRI that are not present in the FDG-fPET signal, such as magnetic field and haemoglobin-based artefacts (Liu, 2017; Ward 
et al., 2020). The disparity in the results from the two modalities is augurs well for gaining deeper insights to improve our understanding of cognition-brain connectivity relationships.

In conclusion, this study is an important step in revealing that cognition is supported by a domain-general hemodynamic and metabolic processing. Crucially, the metabolic processes appear to be more spatially defined by frontoparietal areas, whereas the hemodynamic processes throughout the frontal, parietal, temporal, and occipital areas collectively support cognition. These findings demonstrate the unique advantages that simultaneous FDG-PET/fMRI has to provide a comprehensive understanding of the neural mechanisms that underpin cognition, and highlights the importance of multimodality imaging in cognitive neuroscience research.

\section{Materials and Methods}

All methods were reviewed by the Monash University Human Research Ethics Committee, following the Australian National Statement of Ethical Conduct in Human Research (2007). Participants provided informed consent to participate in the study. Administration of ionising radiation was approved by the Monash Health Principal Medical Physicist, following the Australian Radiation Protection and Nuclear Safety Agency Code of Practice (2005). Data from this study is available on OpenNeuro with the accession number ds002898. The Data Descriptor for this study with detailed acquisition and validation analyses is provided in Jamadar et al. (2020), and results of the comparison between fPET, static PET, and BOLD-fMRI connectomes is presented in Jamadar et al. (2021).

\section{Participants}

Twenty-eight participants were recruited from the general community. An initial screening interview assessed that these participants had no history of hypertension or diabetes, had no neurological and psychiatric illness, or were on psychoactive medication 
affecting cognitive functioning or cerebral blood flow. Participants were also screened for claustrophobia, non-MR compatible implants, clinical or research PET scan in the past 12 months, and women were screened for current or suspected pregnancy. Prior to the scan, participants were directed to consume a high-protein/low-sugar diet for $24 \mathrm{~h}$, fast for $6 \mathrm{~h}$, and drink 2-6 glasses of water. Blood sugar level was measured using an Accu-Check Performa (model NC, Mannheim, Germany); all participants had blood sugar levels $<10 \mathrm{mmol} / \mathrm{L}$ with none exceeding $4.73 \mathrm{mmol} / \mathrm{L}$. Two participants were excluded for further analyses, as one participant did not complete the full scan and the infusion pump failed for one participant. The total sample $(\mathrm{n}=26,77 \%$ females) were aged between $18-23$ years (mean age $=19.50$ years, $\mathrm{SD}=1.36$ years), right-handed (Oldfield, 1971), English speakers (Table S1 for summary demographics). Although the sample consisted of significantly larger proportion of females, there were no significant $(p>0.5)$ gender-based differences observed in their demographics (Figure S1).

\section{Neuropsychological Test Battery}

Prior to the scan, participants completed a test battery consisting of six neuropsychological test or scales assessing a wide range of cognitive functioning: (1) Hopkins Verbal Learning Test-Revised (Benedict et al., 1998), (2) Symbol digit modalities test (Smith, 1991), (3) Stroop Neuropsychological Screening test (Trenerry et al., 1989), (4) single-letter controlled oral word association test (COWAT; Ruff et al., 1996), (5) Colour Trails Task (Reitan, 1958), and the (6) Center of Epidemiologic Studies Depression Scale Revised (Radloff, 1977). Full details of the neuropsychological tests are provided in the Appendix.

Overall, the five tests produced 14 cognitive outcome variables, which are summarised in Table 1 (Results). Relationships between the cognitive outcome variables were explored via Pearson's correlations for continuous outcome variables and Spearman 
correlation for ordinal outcome variables. Relationships were considered significant at a false discovery rate corrected $\mathrm{p}$ value of 0.0062 (Benjamini and Hochberg, 1995)

\section{Simultaneous MR-PET data acquisition}

Following the completion of the cognitive battery (approximately 30 minutes), participants underwent preparation for the simultaneous MR-PET scan. They were first cannulated in the vein in each forearm, and a 10-ml baseline blood sample was taken. For all participants, the left cannula was used for FDG infusion, and the right cannula was used for blood sampling.

Participants underwent a 95-min simultaneous MR-PET scan in a Siemens (Erlangen) Biograph 3-Tesla molecular MR scanner. Participants were positioned supine in the scanner bore with their head in a 16-channel radiofrequency head coil and were instructed to lie as still as possible with eyes open and think of nothing in particular. FDG (average dose 233 MBq) was infused over the course of the scan at a rate of $36 \mathrm{~mL} / \mathrm{h}$ using a BodyGuard 323 MR-compatible infusion pump (Caesarea Medical Electronics, Caesarea, Israel). Infusion onset was locked to the onset of the PET scan.

Plasma radioactivity levels were measured throughout the duration of the scan. At 10minutes post-infusion onset, a $10 \mathrm{~mL}$ of blood sample was taken from the right forearm using a vacutainer; the time of the 5-mL mark was noted for subsequent decay correction.

Subsequent blood samples were taken at 10-minute intervals for a total of 10 samples for the duration of the scan. Immediately following blood sampling, the sample was placed in a Heraeus Megafuge 16 centrifuge (ThermoFisher Scientific, Osterode, Germany) and spun at $2000 \mathrm{rpm}$ for 5 minutes; $1000 \mu \mathrm{L}$ plasma was pipetted, transferred to a counting tube, and placed in a well counter for 4 minutes. The count start time, total number of counts, and counts per minute were recorded for each sample. The average radioactivity concentration 
persistently increased over time with the lowest relative rate occurring at the end of the acquisition.

\section{MRI pre-processing}

For the structural $\mathrm{T}_{1}$ image, the brain was extracted in Freesurfer, then registered to MNI152 space using Advanced Normalization Tools (ANTs). The gray matter, white matter, and brain cortex labels of the structural $\mathrm{T}_{1}$ image were segmented into 82 regions using Freesurfer with Desikan-Killiany Atlas (Diedrichsen et al., 2009).

The six blocks of EPI scans for all participants (a total of 1452 volumes) underwent a standard fMRI pre-processing pipeline. Specifically, all scans were brain extracted (FSL BET, Smith, 2002), motion corrected (FSL MCFLIRT, Jenkinson et al., 2002), slice timing corrected (FSL, using Fourier-space time-series phase-shifting) and band-pass filtered $(0.1>\mathrm{Hz}>0.01)$ to remove low-frequency noise (FSL, Jenkinson et al., 2012), and spatially smoothed using a Gaussian kernel of FWHM of $8 \mathrm{~mm}$. Across subjects, the average mean framewise translation motion was $0.41 \mathrm{~mm}$, maximum was $1.09 \mathrm{~mm}$.

\section{PET image reconstruction and pre-processing}

The 5700-s list-mode PET data for each subject were binned into 356 3D sinogram frames each of 16-s interval. The attenuation for all required data was corrected via the pseudo-CT method (Burgos et al., 2014). Ordinary Poisson-Ordered Subset Expectation Maximization algorithm ( 3 iterations, 21 subsets) with point spread function correction was used to reconstruct 3D volumes from the sinogram frames. The reconstructed DICOM slices were converted to NIFTI format with size $344 \times 344 \times 127$ (voxel size: $2.09 \times 2.09 \times 2.03 \mathrm{~mm}^{3}$ ) for each volume. A 5-mm FWHM Gaussian postfilter was applied to each 3D volume. All 3D volumes were temporally concatenated to form a 4D $(344 \times 344 \times 127 \times 356)$ NIFTI volume. A guided motion correction method using simultaneously acquired MRI was applied to 
correct the motion during the PET scan. We retained the 22516 -s volumes commencing from the 30-minute timepoint, which matched the start of the BOLD-fMRI EPI acquisition, for further analyses.

The 225 PET volumes were motion corrected (FSL MCFLIRT, Jenkinson et al., 2002); the mean PET image was brain extracted and used to mask the $4 \mathrm{D}$ data. The fPET data were further processed using a spatiotemporal gradient filter to estimate the short-term change in glucose uptake from the cumulative glucose uptake that was measured (Jamadar et al., 2020). The filter removed the accumulating effect of the radiotracer and other lowfrequency components of the signal to isolate short-term resting-state fluctuations. This approach intrinsically adjusted for the mean signal while avoiding global-signal regression and other approaches that may create spurious anticorrelations in the data (Murphy and Fox, 2017). Due to radiotracer dynamics, it was not expected that the fPET sensitivity would be uniform across the 60 minutes of the resting-state data acquisition. As the radiotracer accumulated in the brain, it was anticipated that the signal-to-noise ratio (SNR) of the PET image reconstruction would progressively improve. The spatiotemporal filter has been described extensively in our previous work (Jamadar et al., 2021; Jamadar et al., 2020). 


\section{Functional and Metabolic Connectivity Analyses}

For fPET and fMRI, time series were extracted for each of the 82 regions of interest (ROIs) from the segmentation of the T1 - weighted image, interpolated using an ANTs rigid registration (Avants et al., 2011). To construct a connectivity matrix, Pearson's correlation coefficients were estimated between the timeseries from pairs of regions. This produced a per-subject per- modality $26 \times 82 \times 82$ matrix corresponding to the 60 minutes of restingstate in the experimental protocol. For interpretation of connectivity patterns, the 82 ROIs were anatomically sorted as defined by the Desikan-Killiany Atlas (i.e., frontal, parietal, occipital, subcortical, temporal; Diedrichsen et al., 2009).

\section{Partial Least Squares Analyses}

We used Partial Least Squares (PLS) analyses to assess the multidimensional functional relationships between (1) the hemodynamic connectome and cognition, as well as (2) the metabolic connectome and cognition (Krishnan et al., 2011; McIntosh and Lobaugh, 2004) (Figure 1). PLS is an unsupervised multivariate machine learning technique that extracts the common information between two datasets (i.e., brain connectivity $[\mathbf{X}]$ and cognitive responses [Y] ) by finding orthogonal sets of latent variables with maximum covariance, which reflect the linear combinations of the original data. In our case, the brain connectivity is either the hemodynamic connectome $\left[\mathbf{X}_{\mathbf{F}}\right]$ or metabolic connectome $\left[\mathbf{X}_{\mathbf{M}}\right]$. Prior to the application of PLS, the upper triangle of the hemodynamic connectivity matrix and the metabolic connectivity matrix (i.e., 3321 connections, respectively) were vectorized and stacked as participant by connection resulting in matrices sized $26 \times 3321$, respectively. The cognition matrix was sized at $26 \times 14$. These subject-specific the hemodynamic connectivity matrix $\left(\mathbf{X}_{\mathbf{F}}\right)$, metabolic connectivity $\left(\mathbf{X}_{\mathbf{M}}\right)$ matrices and the cognitive response matrix (Y) were subsequently z-scored column-wise. 
First, the correlation matrix between the brain connectivity $(\mathbf{X})$ and cognition matrix (Y) is computed $\mathbf{R}=\mathbf{X}^{\mathbf{T}} \mathbf{Y}$ and single value decomposition (Eckart and Young 1936) is next applied to that connectivity-cognition matrix, resulting in $\mathbf{R}=\mathbf{U S V}^{\mathbf{T}}$. The outcome of the single value decomposition is a set of mutually orthogonal latent variables, whereby $\mathbf{U}$ and $\mathbf{V}$ are orthogonal matrices consisting of left and right singular vectors and $\mathbf{S}$ is a diagonal matrix of singular values. The number of latent variables is equal to the rank of the covariance matrix R, which is the smaller of its dimensions. Every latent variable is associated with 1) a singular value (diagonal elements of $\mathbf{S}$ ) indicated the correlation explained by that latent variable, 2) a vector of singular values $\mathbf{U}$, which represent the behavioural saliences, and 3) a vector of singular values $\mathbf{V}$, which represent the brain saliences. The behavioural saliences indicate how strong each one of the cognitive variables contributes to the brain-design correlation explained by a particular latent variable. Similarly, the brain saliences $\mathbf{V}$ express how strong every connection contributes to the brain-design correlation explained by a particular latent variable. The projection of every subject's original connectivity (in $\mathbf{X}$ ) onto the multivariate brain salience pattern (in $\mathbf{V}$ ) results in brain scores $\mathbf{L}_{\mathbf{x}}=\mathbf{X V}$. Brain scores measure the similarity of a subject's individual brain data with the salient brain pattern. Similarly, cognitive scores can be computed by $\mathbf{L y}=\mathbf{Y U}$, which represent a projection of every subject's design variable onto the respective design saliences. Finally, brain loadings (or weights) were computed as the Pearson's correlation between the brain connectivity matrix and the PLS analysis-derived brain scores. Similarly, cognitive loadings were computed as the Pearson's correlations between cognitive variables and the PLS analysisderived cognition scores across the cohort. Loadings can be interpreted as indexing the degree contribution of each variable to the PLS analysis-derived latent variable. Loadings are only interpreted for significant latent variables. 
The significance of each latent variable is assessed via permutation tests (5000 iterations) of the singular values from the single value decomposition of the brain and cognition matrices and the reliability of each connectivity estimate to the latent variable is assessed via bootstrap resampling (5000 iterations). The reliability of the loading of each connection onto the brain-cognition relationship in each latent variable is established via bootstrap (5000 iterations). A connection with a positive bootstrapped loading contributes positively and reliably to the brain-cognition correlation obtained for that latent variable, whereas a connection with a negative high bootstrapped loading contributes negatively and reliably to the brain-cognition relationship. Bootstrapping is also used to construct $95 \%$ confidence intervals on the brain-cognition correlations.

\section{Hemodynamic versus metabolic connectivity in relation to cognition}

To compare the brain connections that contributed to the hemodynamic connectomecognition relationship and metabolic connectome-cognition relationship, the scalar product between the brain saliences (U) resulting from each PLS were computed for significant latent variables. Similarly, to compare the cognitive responses that contributed to the metabolic connectome-cognition relationship and functional connectome-relationship, we calculated the dot product between the behavioural saliences $(\mathbf{V})$ that resulted from both PLS analyses. A scalar product of 0 suggests no overlap across modalities and a scalar product of 1 suggest strong overlap across modalities (i.e., fPET and fMRI). Finally, to identify the anatomical location of similar brain loadings across modalities, Pearson's correlations was performed on the brain loadings matrices of both modalities. This results in a matrix of cosine similarity between the two modalities.

\section{Acknowledgements}


This work was supported by an Australian Research Council (ARC) Linkage Project

(LP170100494) that includes financial support from Siemens Healthineers. Jamadar is supported by an Australian National Health and Medical Research Council fellowship (APP1174164). Egan, Ward, and Jamadar are supported by the ARC Centre of Excellence for Integrative Brain Function (CE140100007).

\section{Data and Code Availability}

The dataset containing the demographic, fMRI, PET, T1 structural and gradient field maps is freely available in BIDS format (Gorgolewski et al., 2016) from the OpenNeuro repository (http://openneuro.org) with the accession number ds002898 (Jamadar et al., 2020). Data and code that generated the results is available on the Open Science Network (DOI 10.17605/OSF.IO/DQN5S).

\section{Competing interests}

The authors declare no competing interests.

\section{References}

Assem M, Glasser MF, Van Essen DC, Duncan J. 2020. A Domain-General Cognitive Core Defined in Multimodally Parcellated Human Cortex. Cereb Cortex 30:4361-4380. doi:10.1093/cercor/bhaa023

Avants BB, Tustison NJ, Song G, Cook PA, Klein A, Gee JC. 2011. A reproducible evaluation of ANTs similarity metric performance in brain image registration. NeuroImage 54:2033-2044. doi:10.1016/j.neuroimage.2010.09.025

Avena-Koenigsberger A, Misic B, Sporns O. 2018. Communication dynamics in complex brain networks. Nat Rev Neurosci 19:17-33. doi:10.1038/nrn.2017.149

Barack DL, Krakauer JW. 2021. Two views on the cognitive brain. Nat Rev Neurosci 22:359-371. doi:10.1038/s41583-021-00448-6

Benedict RHB, Schretlen D, Groninger L, Brandt J. 1998. Hopkins Verbal Learning Test Revised: Normative Data and Analysis of Inter-Form and Test-Retest Reliability. Clin Neuropsychol 12:43-55. doi:10.1076/clin.12.1.43.1726

Benjamini Y, Hochberg Y. 1995. Controlling the False Discovery Rate: A Practical and Powerful Approach to Multiple Testing. J R Stat Soc Ser B Methodol 57:289-300. 
bioRxiv preprint doi: https://doi.org/10.1101/2021.09.06.459214; this version posted September 7, 2021. The copyright holder for this preprint (which was not certified by peer review) is the author/funder, who has granted bioRxiv a license to display the preprint in perpetuity. It is made available under aCC-BY-NC-ND 4.0 International license.

Biswal B, Yetkin FZ, Haughton VM, Hyde JS. 1995. Functional connectivity in the motor cortex of resting human brain using echo-planar MRI. Magn Reson Med 34:537-541. doi:10.1002/mrm.1910340409

Botvinick MM, Cohen JD, Carter CS. 2004. Conflict monitoring and anterior cingulate cortex: an update. Trends Cogn Sci 8:539-546. doi:10.1016/j.tics.2004.10.003

Burgos N, Cardoso MJ, Thielemans K, Modat M, Pedemonte S, Dickson J, Barnes A, Ahmed R, Mahoney CJ, Schott JM, Duncan JS, Atkinson D, Arridge SR, Hutton BF, Ourselin S. 2014. Attenuation Correction Synthesis for Hybrid PET-MR Scanners: Application to Brain Studies. IEEE Trans Med Imaging 33:2332-2341. doi:10.1109/TMI.2014.2340135

Chein JM, Schneider W. 2005. Neuroimaging studies of practice-related change: fMRI and meta-analytic evidence of a domain-general control network for learning. Brain Res Cogn Brain Res 25:607-623. doi:10.1016/j.cogbrainres.2005.08.013

Chen Z, Jamadar SD, Li S, Sforazzini F, Baran J, Ferris N, Shah NJ, Egan GF. 2018. From simultaneous to synergistic MR-PET brain imaging: A review of hybrid MR-PET imaging methodologies. Hum Brain Mapp 39:5126-5144. doi:10.1002/hbm.24314

Cole MW, Repovs G, Anticevic A. 2014. The frontoparietal control system: A central role in mental health. Neurosci Rev J Bringing Neurobiol Neurol Psychiatry 20:652-664. doi:10.1177/1073858414525995

Contreras M, Billeke P, Vicencio S, Madrid C, Perdomo G, González M, Torrealba F. 2012. A Role for the Insular Cortex in Long-Term Memory for Context-Evoked Drug Craving in Rats. Neuropsychopharmacology 37:2101-2108. doi:10.1038/npp.2012.59

Dehaene S, Naccache L, Le Clec'H G, Koechlin E, Mueller M, Dehaene-Lambertz G, van de Moortele P-F, Le Bihan D. 1998. Imaging unconscious semantic priming. Nature 395:597-600. doi:10.1038/26967

Diedrichsen J, Balsters JH, Flavell J, Cussans E, Ramnani N. 2009. A probabilistic MR atlas of the human cerebellum. NeuroImage 46:39-46. doi:10.1016/j.neuroimage.2009.01.045

Duncan J. 2001. An adaptive coding model of neural function in prefrontal cortex. Nat Rev Neurosci 2:820-829. doi:10.1038/35097575

Gorgolewski KJ, Auer T, Calhoun VD, Craddock RC, Das S, Duff EP, Flandin G, Ghosh SS, Glatard T, Halchenko YO, Handwerker DA, Hanke M, Keator D, Li X, Michael Z, Maumet C, Nichols BN, Nichols TE, Pellman J, Poline J-B, Rokem A, Schaefer G, Sochat V, Triplett W, Turner JA, Varoquaux G, Poldrack RA. 2016. The brain imaging data structure, a format for organizing and describing outputs of neuroimaging experiments. Sci Data 3:160044. doi:10.1038/sdata.2016.44

Goyal N, Moraczewski D, Thomas AG. 2020a. Computationally replicating the Smith et al. (2015) positive-negative mode linking functional connectivity and subject measures. bioRxiv 2020.04.23.058313. doi:10.1101/2020.04.23.058313

Goyal N, Moraczewski D, Thomas AG. 2020b. Computationally replicating the Smith et al. (2015) positive-negative mode linking functional connectivity and subject measures. bioRxiv 2020.04.23.058313. doi:10.1101/2020.04.23.058313

Hahn A, Breakspear M, Rischka L, Wadsak W, Godbersen GM, Pichler V, Michenthaler P, Vanicek T, Hacker M, Kasper S, Lanzenberger R, Cocchi L. 2020. Reconfiguration of functional brain networks and metabolic cost converge during task performance. eLife 9:e52443. doi:10.7554/eLife.52443

Hearne LJ, Mattingley JB, Cocchi L. 2016. Functional brain networks related to individual differences in human intelligence at rest. Sci Rep 6:32328. doi:10.1038/srep32328

Jamadar Sharna D., Ward PGD, Close TG, Fornito A, Premaratne M, O'Brien K, Stäb D, Chen Z, Shah NJ, Egan GF. 2020. Simultaneous BOLD-fMRI and constant infusion 
bioRxiv preprint doi: https://doi.org/10.1101/2021.09.06.459214; this version posted September 7, 2021. The copyright holder for this preprint (which was not certified by peer review) is the author/funder, who has granted bioRxiv a license to display the preprint in perpetuity. It is made available under aCC-BY-NC-ND 4.0 International license.

FDG-PET data of the resting human brain. Sci Data 7:363. doi:10.1038/s41597-02000699-5

Jamadar SD, Ward PGD, Liang EX, Orchard ER, Chen Z, Egan GF. 2021. Metabolic and Hemodynamic Resting-State Connectivity of the Human Brain: A High-Temporal Resolution Simultaneous BOLD-fMRI and FDG-fPET Multimodality Study. Cereb Cortex bhaa393. doi:10.1093/cercor/bhaa393

Jamadar Sharna D, Ward PGD, Thomas G. C, Alex F, Premaratne M, O’Brien K, Staeb D, Chen Z, Shah J, Egan GF. 2020. Monash rsPET-MRI. OpenNeuro.

Jeneson A, Mauldin KN, Hopkins RO, Squire LR. 2011. The role of the hippocampus in retaining relational information across short delays: The importance of memory load. Learn Mem 18:301-305. doi:10.1101/1m.2010711

Jenkinson M, Bannister P, Brady M, Smith S. 2002. Improved optimization for the robust and accurate linear registration and motion correction of brain images. NeuroImage 17:825-841. doi:10.1016/s1053-8119(02)91132-8

Jenkinson M, Beckmann CF, Behrens TEJ, Woolrich MW, Smith SM. 2012. FSL. NeuroImage, 20 YEARS OF fMRI 62:782-790. doi:10.1016/j.neuroimage.2011.09.015

Judenhofer MS, Wehrl HF, Newport DF, Catana C, Siegel SB, Becker M, Thielscher A, Kneilling M, Lichy MP, Eichner M, Klingel K, Reischl G, Widmaier S, Röcken M, Nutt RE, Machulla H-J, Uludag K, Cherry SR, Claussen CD, Pichler BJ. 2008. Simultaneous PET-MRI: a new approach for functional and morphological imaging. Nat Med 14:459-465. doi:10.1038/nm1700

Krishnan A, Williams LJ, McIntosh AR, Abdi H. 2011. Partial Least Squares (PLS) methods for neuroimaging: A tutorial and review. NeuroImage 56:455-475. doi:10.1016/j.neuroimage.2010.07.034

Liu TT. 2017. Reprint of "Noise contributions to the fMRI signal: An Overview." NeuroImage 154:4-14. doi:10.1016/j.neuroimage.2017.05.031

Marek S, Dosenbach NUF. 2018. The frontoparietal network: function, electrophysiology, and importance of individual precision mapping. Dialogues Clin Neurosci 20:133140.

McIntosh AR, Lobaugh NJ. 2004. Partial least squares analysis of neuroimaging data: applications and advances. NeuroImage 23:S250-S263. doi:10.1016/j.neuroimage.2004.07.020

McIntosh AR, Misic B. 2013. Multivariate Statistical Analyses for Neuroimaging Data. Annu Rev Psychol 64:499-525. doi:10.1146/annurev-psych-113011-143804

Menon V, Uddin LQ. 2010. Saliency, switching, attention and control: a network model of insula function. Brain Struct Funct 214:655-667. doi:10.1007/s00429-010-0262-0

Mier W, Mier D. 2015. Advantages in functional imaging of the brain. Front Hum Neurosci 9. doi:10.3389/fnhum.2015.00249

Miller EK, Cohen JD. 2001. An Integrative Theory of Prefrontal Cortex Function. Annu Rev Neurosci 24:167-202. doi:10.1146/annurev.neuro.24.1.167

Müller NCJ, Konrad BN, Kohn N, Muñoz-López M, Czisch M, Fernández G, Dresler M. 2018. Hippocampal-caudate nucleus interactions support exceptional memory performance. Brain Struct Funct 223:1379-1389. doi:10.1007/s00429-017-1556-2

Murphy K, Fox MD. 2017. Towards a consensus regarding global signal regression for resting state functional connectivity MRI. NeuroImage 154:169-173. doi:10.1016/j.neuroimage.2016.11.052

Oldfield RC. 1971. The assessment and analysis of handedness: The Edinburgh inventory. Neuropsychologia 9:97-113. doi:10.1016/0028-3932(71)90067-4 
bioRxiv preprint doi: https://doi.org/10.1101/2021.09.06.459214; this version posted September 7, 2021. The copyright holder for this preprint (which was not certified by peer review) is the author/funder, who has granted bioRxiv a license to display the preprint in perpetuity. It is made available under aCC-BY-NC-ND 4.0 International license.

Radloff LS. 1977. The CES-D Scale: A Self-Report Depression Scale for Research in the General Population. Appl Psychol Meas 1:385-401. doi:10.1177/014662167700100306

Raichle ME. 2011. The Restless Brain. Brain Connect 1:3-12. doi:10.1089/brain.2011.0019

Raichle ME. 2009. A brief history of human brain mapping. Trends Neurosci 32:118-126. doi:10.1016/j.tins.2008.11.001

Rischka L, Gryglewski G, Pfaff S, Vanicek T, Hienert M, Klöbl M, Hartenbach M, Haug A, Wadsak W, Mitterhauser M, Hacker M, Kasper S, Lanzenberger R, Hahn A. 2018. Reduced task durations in functional PET imaging with [18F]FDG approaching that of functional MRI. NeuroImage 181:323-330. doi:10.1016/j.neuroimage.2018.06.079

Ruff RM, Light RH, Parker SB, Levin HS. 1996. Benton controlled oral word association test: Reliability and updated norms. Arch Clin Neuropsychol 11:329-338. doi:10.1093/arclin/11.4.329

Sala A, Perani D. 2019. Brain Molecular Connectivity in Neurodegenerative Diseases: Recent Advances and New Perspectives Using Positron Emission Tomography. Front Neurosci 13:617. doi:10.3389/fnins.2019.00617

Schultz DH, Ito T, Solomyak LI, Chen RH, Mill RD, Anticevic A, Cole MW. n.d. Global connectivity of the fronto-parietal cognitive control network is related to depression symptoms in the general population. Netw Neurosci 17.

Shenhav A, Botvinick MM, Cohen JD. 2013. The Expected Value of Control: An Integrative Theory of Anterior Cingulate Cortex Function. Neuron 79:217-240. doi:10.1016/j.neuron.2013.07.007

Shokri-Kojori E, Tomasi D, Alipanahi B, Wiers CE, Wang G-J, Volkow ND. 2019. Correspondence between cerebral glucose metabolism and BOLD reveals relative power and cost in human brain. Nat Commun 10:690. doi:10.1038/s41467-01908546-x

Smith A. 1991. Symbol Digit Modalities Test. Los Angeles: CA: Western Psychological Services.

Smith SM. 2002. Fast robust automated brain extraction. Hum Brain Mapp 17:143-155. doi:10.1002/hbm. 10062

Smith SM, Nichols TE, Vidaurre D, Winkler AM, Behrens TEJ, Glasser MF, Ugurbil K, Barch DM, Van Essen DC, Miller KL. 2015a. A positive-negative mode of population covariation links brain connectivity, demographics and behavior. Nat Neurosci 18: $1565-1567$. doi:10.1038/nn.4125

Smith SM, Nichols TE, Vidaurre D, Winkler AM, Behrens TEJ, Glasser MF, Ugurbil K, Barch DM, Van Essen DC, Miller KL. 2015b. A positive-negative mode of population covariation links brain connectivity, demographics and behavior. Nat Neurosci 18:1565-1567. doi:10.1038/nn.4125

Sporns O. 2013. The human connectome: Origins and challenges. NeuroImage, Mapping the Connectome 80:53-61. doi:10.1016/j.neuroimage.2013.03.023

Sporns O, Tononi G, Kötter R. 2005. The Human Connectome: A Structural Description of the Human Brain. PLOS Comput Biol 1:e42. doi:10.1371/journal.pcbi.0010042

Trenerry MR, Crosson B, DeBoe J, Leber WR. 1989. Stroop neuropsychological screening test manual. Lutz, FL: Psychological Assessment Resources.

Validity of the Trail Making Test as an Indicator of Organic Brain Damage - Ralph M. Reitan, 1958. n.d. https://journals.sagepub.com/doi/10.2466/pms.1958.8.3.271

Villien M, Wey H-Y, Mandeville JB, Catana C, Polimeni JR, Sander CY, Zürcher NR, Chonde DB, Fowler JS, Rosen BR, Hooker JM. 2014. Dynamic functional imaging of brain glucose utilization using fPET-FDG. NeuroImage 100:192-199. doi:10.1016/j.neuroimage.2014.06.025 
bioRxiv preprint doi: https://doi.org/10.1101/2021.09.06.459214. this version posted September 7, 2021. The copyright holder for this preprint (which was not certified by peer review) is the author/funder, who has granted bioRxiv a license to display the preprint in perpetuity. It is made available under aCC-BY-NC-ND 4.0 International license.

Wallis G, Stokes M, Cousijn H, Woolrich M, Nobre AC. 2015. Frontoparietal and Cinguloopercular Networks Play Dissociable Roles in Control of Working Memory. J Cogn Neurosci 27:2019-2034. doi:10.1162/jocn_a_00838

Ward PGD, Orchard ER, Oldham S, Arnatkevičiūtè A, Sforazzini F, Fornito A, Storey E, Egan GF, Jamadar SD. 2020. Individual differences in haemoglobin concentration influence bold fMRI functional connectivity and its correlation with cognition. NeuroImage 221:117196. doi:10.1016/j.neuroimage.2020.117196

Yakushev I, Drzezga A, Habeck C. 2017. Metabolic connectivity: methods and applications. Curr Opin Neurol 30:677-685. doi:10.1097/WCO.0000000000000494

Ziegler G, Dahnke R, Winkler AD, Gaser C. 2013. Partial least squares correlation of multivariate cognitive abilities and local brain structure in children and adolescents. NeuroImage 82:284-294. doi:10.1016/j.neuroimage.2013.05.088

Zimmermann J, Griffiths JD, McIntosh AR. 2018. Unique Mapping of Structural and Functional Connectivity on Cognition. J Neurosci 38:9658-9667. doi:10.1523/JNEUROSCI.0900-18.2018 
bioRxiv preprint doi: https://doi.org/10.1101/2021.09.06.459214; this version posted September 7, 2021. The copyright holder for this preprint (which was not certified by peer review) is the author/funder, who has granted bioRxiv a license to display the preprint in perpetuity. It is made available under aCC-BY-NC-ND 4.0 International license. 